\title{
Perbedaan Hasil Belajar Fisika Melalui Penerapan Model Pembelajaran Kooperatif Tipe Snowball Throwing dan Tipe Talking Stick pada Siswa Kelas XI SMA Khatolik Santo Andreas Palu
}

\author{
Fienny Putri Lela Lekka, Muhammad Ali, dan Syamsu \\ kifli.lela@gmail.com \\ Program Studi Pend. Fisika, Jurusan Pendidikan MIPA, Universitas Tadulako \\ Jl. Soekarno Hatta KM. 9 Kampus Bumi Tadulako Tondo Palu - Sulawesi Tengah
}

\begin{abstract}
Abstrak - Penelitian ini bertujuan untuk mengetahui ada tidaknya perbedaan hasil belajar fisika melalui penerapan model pembelajaran kooperatif tipe Snowball Throwing dan tipe Talking Stick pada siswa kelas XI SMA Khatolik Santo Andreas Palu. Jenis penelitian yang digunakan adalah eksperimen dengan desain "The equivalent pretest-posttest design". Sampel dipilih dengan menggunakan teknik purposive sampling dan menghasilkan kelas XI IPA 1 sebagai kelas eksperimen ke-1 dan kelas XI IPA 2 sebagai kelas eksperimen ke-2. Instrumen yang digunakan berupa tes hasil belajar fisika dalam bentuk pilihan ganda. Berdasarkan hasil pengolahan data, diperoleh rerata skor posttest hasil belajar fisika siswa kelas eksperimen ke-1 adalah 25,30 dengan standar deviasi 3,89 dari 35 skor total. Untuk kelas eksperimen ke-2 diperoleh rerata skor posttest adalah 21,90 dengan standar deviasi 5,32 dari 35 skor total. Analisis data tes dilakukan dengan teknik statistik uji-t dua pihak untuk menguji perbedaan rerata skor hasil belajar siswa dengan taraf signifikan $a=0,05$. Diperoleh nilai hasil $t_{\text {hitung }}=2,46$ dan $t_{\text {tabel }}=2,02$. Ini berarti nilai $t_{\text {hitung }}$ berada diluar daerah penerimaan $\mathrm{H}_{0}$. Sehingga dapat disimpulkan bahwa, ada terdapat perbedaan hasil belajar fisika melalui penerapan model pembelajaran kooperatif tipe Snowball Throwing dan tipe Talking Stick pada siswa kelas XI SMA Khatolik Santo Andreas Palu.
\end{abstract}

kata kunci : tipe snowball throwing, tipe talking stick, hasil belajar

\section{PENDAHULUAN}

Guru merupakan kunci utama dalam meningkatkan mutu dan kualitas pendidikan. Mereka berada dititik utama dalam setiap usaha perubahan pendidikan yang diarahkan pada perubahan kualitatif. Guru mempunyai tanggung jawab untuk mengatur, mengarahkan, dan menciptakan suasana yang mendorong siswa untuk melaksanakan berbagai kegiatan dalam proses pembelajaran di kelas. Salah satu tugas yang tidak boleh diabaikan oleh guru adalah pemilihan metode yang tepat sesuai dengan materi atau konsep yang akan diajarkan. Metode pembelajaran yang akan dipakai oleh guru akan banyak berpengaruh terhadap cara belajar siswa yang mana setiap siswa mempunyai cara belajar yang berbedabeda [1].

Menurut Slameto [2] guru merupakan sumber utama dalam pembelajaran yang memegang peranan penting dalam pembelajaran. Berdasarkan hasil wawancara dengan guru IPA pada pembelajaran fisika penjelasan materi membutuhkan waktu hingga beberapa kali pengulangan agar siswa dapat menerima informasi yang diberikan terkait materi yang disampaikan oleh guru.
Proses pembelajaran dipengaruhi dua faktor yaitu faktor internal dan faktor eksternal. Faktor internal adalah faktor yang berasal dari dalam diri guru dan siswa seperti rasa malas, bosan, dan gembira. Sedangkan faktor eksternal adalah faktor yang berasal dari guru dan siswa seperti lingkungan sekolah, ruang belajar, model pembelajaran, dan sebagainya. Pada proses pembelajaran berlangsung, guru harus pandai memilih penggunaan model pembelajaran yang tepat. Gintoe [3] menyatakan dengan pembelajaran kooperatif diharapkan siswa dapat lebih intensif belajar hingga akan menguasai materi pelajaran dengan mudah, karena siswa lebih mudah memahami penjelasan dari kawannya dibanding penjelasan guru karena taraf pengetahuan serta pemikiran mereka lebih sejalan dan sepadan.

Pembelajaran kooperatif terdiri dari banyak tipe diantaranya: kooperatif tipe Snowball Throwing dan Talking Stick. Kedua tipe pembelajaran kooperatif ini memiliki banyak kesamaan diantaranya sama-sama menuntut siswa untuk lebih aktif serta di ajarkan dalam bentuk sebuah permainan sehingga proses belajar mengajar berjalan menyenangkan. 
Model pembelajaran kooperatif tipe Snowball Throwing merupakan suatu cara penyajian pelajaran dengan cara siswa berkreatifitas membuat soal dan menyelesaikan soal yang telah dibuat oleh temannya dengan sebaik- baiknya, sedangkan model pembelajaran kooperatif tipe Talking stick adalah suatu model pembelajaran kelompok sama seperti Snowball Throwing, tetapi dalam penerapan model ini, memanfaatkan tongkat oleh sebab itu disebut Talking Stick .

Berdasarkan uraian diatas, peneliti bermaksud untuk melakukan penelitian sejauh mana perbedaan hasil belajar fisika melalui penerapan model pembelajaran Kooperatif tipe Snowball Throwing dan tipe Talking Stick pada siswa kelas XI SMA Khatolik Santo Andreas Palu.

\section{METODE PENELITIAN}

Sampel diambil dengan pertimbangan tertentu dari guru mata pelajaran fisika pada kedua kelas di sekolah tersebut. Kedua kelas yang dipilih merupakan kelas yang dianggap homogen secara akademik.

Adapun desain penelitian yang digunakan adalah the equivalent pretest-posttest design. Menurut Arikunto [4] desain ini digunakan untuk kelompok yang telah ada sebelumnya dan pengambilan kelompoknya dilakukan tidak secara acak (random). Desain penelitian yang digunakan seperti pada Tabel 1.

TABEL 1 DESAIN PENELITIAN

\begin{tabular}{|c|c|c|c|c|}
\hline \multicolumn{2}{|c|}{ Kelompok } & Pretest & Perlakuan & Postest \\
\hline \multicolumn{2}{|c|}{ KE-1 } & $\mathrm{O}_{1}$ & $\mathrm{X}_{1}$ & $\mathrm{O}_{2}$ \\
\hline \multicolumn{2}{|c|}{ KE-2 } & $\mathrm{O}_{1}$ & $X_{2}$ & $\mathrm{O}_{2}$ \\
\hline \multicolumn{5}{|c|}{ Keterangan: } \\
\hline KE-1 & \multicolumn{4}{|c|}{ : Kelompok Eksperimen ke-1 } \\
\hline KE-2 & \multicolumn{4}{|c|}{ : Kelompok Eksperimen ke-2 } \\
\hline $\mathrm{X}_{1}$ & \multicolumn{4}{|c|}{ : Model Kooperatif Tipe Snowball Throwing } \\
\hline$X_{2}$ & \multicolumn{4}{|c|}{ : Model Kooperatif Tipe Talking Stick } \\
\hline $\mathrm{O}_{1}$ & \multicolumn{4}{|c|}{ : Tes Awal } \\
\hline $\mathrm{O}_{2}$ & \multicolumn{4}{|c|}{ : Tes Akhir } \\
\hline
\end{tabular}

Penelitian dilakukan di SMA Khatolik Santo Andreas Palu. Populasi dalam penelitian ini adalah seluruh siswa kelas XI IPA SMA Khatolik Santo Andreas Palu tahun pelajaran 2017/2018 yang terdiri dari 3 kelas. Sampel dalam penelitian ini adalah kelas XI IPA 1 yang berjumlah 20 siswa dan XI IPA 2 yang berjumlah 20 siswa. Teknik pengumpulan sampel yang digunakan adalah purposive sampling, yaitu teknik penentuan sampel dengan pertimbangan sistem penempatan siswa di dalam kelas serta waktu belajar yang sama.

Instrumen yang digunakan dalam penelitian ini adalah tes pilihan ganda berjumlah 35 soal, untuk melihat hasil belajar siswa pada mata pelajaran fisika yang telah divalidasi oleh validator ahli. Analisis data dilakukan dengan menganalisis data hasil penelitian menggunakan uji statistik $t$ dua pihak.

\section{HASIL DAN PEMBAHASAN}

\section{A. Hasil Penelitian}

Skor rata-rata pretest kelas eksperimen ke-1 sebesar 12,10 dengan standar deviasi sebesar 2,95 . Sedangkan untuk kelas eksperimen ke-2, skor rata-ratanya sebesar 15,80 dan standar deviasi sebesar 3,69 dari 35 skor total. Selanjutnya pada posttest, skor rata-rata kelas eksperimen ke-1 sebesar 25,30 dengan standar deviasi 3,76 dan untuk kelas eksperimen ke-2 skor rata-ratanya sebesar 21,90 dengan standar deviasi sebesar 4,84 dari 35 skor total. Adapun data hasil penelitian di atas, disajikan pada Tabel 2

TABEL 2 DESKRIPSI SKOR TES HASIL BELAJAR FISIKA SISWA UNTUK KELAS EKSPERIMEN DAN KELAS KONTROL.

\begin{tabular}{lcccc}
\hline \multirow{2}{*}{ Uraian } & \multicolumn{2}{c}{ Pretest } & \multicolumn{2}{c}{ Posttest } \\
\cline { 2 - 5 } & $\begin{array}{c}\text { Eksperim } \\
\text { en ke-1 }\end{array}$ & $\begin{array}{c}\text { Eksperi } \\
\text { men } \\
\text { ke-2 }\end{array}$ & $\begin{array}{c}\text { Eksperi } \\
\text { men } \\
\text { ke-1 }\end{array}$ & $\begin{array}{c}\text { Eksperi } \\
\text { men } \\
\text { ke-2 }\end{array}$ \\
\hline Sampel (n) & 20 & 20 & 20 & 20 \\
Nilai maksimum & 17 & 24 & 32 & 31 \\
Nilai minimum & 8 & 10 & 18 & 12 \\
Skor rata-rata & 12,10 & 15,80 & 25,30 & 21,90 \\
Standar deviasi & 2,95 & 3,69 & 3,76 & 4,84 \\
\hline
\end{tabular}

Uji normalitas data digunakan untuk mengetahui apakah populasi data berdistribusi normal atau tidak. Data yang diuji normalitas adalah data hasil Posttest pada kelas eksperimen ke-1 dan kelas eksperimen ke- 2 . Pengujian normalitas data posttest pada penelitian menggunakan uji Chi-kuadrat dengan kriteria penerimaan $X^{2}$ hitung $<X^{2}$ Tabel, taraf signifikan $\alpha=0,05$, dan derajat kebebasan $\mathrm{dk}=\mathrm{k}-3$. Dari Tabel 3 terlihat bahwa nilai $X^{2}$ hitung kelas eksperimen ke-1 maupun kelas eksperimen ke-2 lebih kecil daripada nilai $X^{2}$ tabel. Artinya, hasil ini menunjukan bahwa data posttest kelas eksperimen ke-1 maupun kelas eksperimen ke2 terdistribusi normal. 
TABEL 3 NORMALITAS DISTRIBUSI TES AKHIR PADA KELAS EKSPERIMEN KE-1

\begin{tabular}{llc}
\hline \multirow{2}{*}{ Uraian } & Eksperimen ke-1 & Eksperimen ke-2 \\
\cline { 2 - 3 } & Test Akhir & Tes Akhir \\
\hline Sampel & 20 & 20 \\
$\chi^{2}$ hitung & 0,97 & 4,95 \\
$\chi^{2}$ tabel & 5,99 & 5,99 \\
\hline
\end{tabular}

Uji homogenitas pada penelitian ini menggunakan uji statistik $F$ dengan taraf signifikansi $a=0,05$. Berdasarkan hasil output uji homogenitas pada Tabel 4 dengan taraf signifikansi $(a=0,05)$, dari data tersebut terlihat bahwa Fitung lebih kecil dari Ftabel, maka berdasarkan kriteria pengambilan keputusan dapat disimpulkan bahwa tidak terdapat perbedaan varians antara kelas eksperimen ke-1 dan kelas eksperimen ke-2 atau dengan kata lain varians antara kelas eksperimen ke-1 dan kelas eksperimen ke-2 adalah sama atau homogen.

TABEL 4 HASIL UJI HOMOGENITAS POSTTEST KELAS EKPERIMEN KE-1 DAN KELAS EKSPERIMEN KE-2

\begin{tabular}{lccc}
\hline \multirow{2}{*}{ Uraian } & \multicolumn{2}{c}{ Posttest } & \\
\cline { 2 - 4 } & \multicolumn{2}{c}{ Eksperimen 1 } & Eksperimen 2 \\
\hline Nilai Varians & 14,12 & 1,66 & 23,41 \\
Variansi Hitung & & 3,68 & \\
Nilai F Tabel & & Homogen & \\
Keputusan & &
\end{tabular}

Setelah terpenuhinya uji normalitas dan homogenitas, maka dilakukan uji beda rata-rata (dua pihak) atau uji-t. Uji-t tersebut diperoleh berdasarkan data posttest. Hasil dapat dilihat pada Tabel 5.

TABEL 5 UJI- $t$ (DUA PIHAK) POSTTEST KELAS EKPERIMEN KE-1 DAN KELAS EKSPERIMEN KE-2

\begin{tabular}{|c|c|c|c|c|}
\hline Kelas & Nilai rata-rata & $\mathrm{t}$ hitung & $\mathrm{t}$ table $(\mathrm{a}=0,05)$ & Keputusan \\
\hline $\begin{array}{l}\text { Ekspe- } \\
\text { rimen }\end{array}$ & 25,30 & & & \\
\hline $\begin{array}{l}\text { ke-1 } \\
\text { Ekspe- } \\
\text { rimen } \\
\text { Ke-2 }\end{array}$ & 21,90 & 2,46 & 2,02 & $\mathrm{H}_{1}$ diterima \\
\hline
\end{tabular}

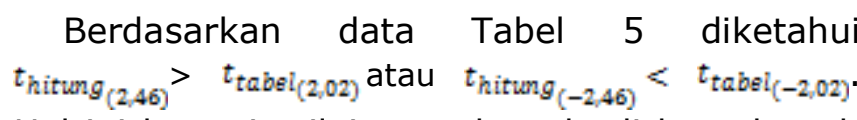
Hal ini berarti, nilai thitung berada di luar daerah penerimaan $\mathrm{H}_{0}$. Dengan demikian $\mathrm{H}_{0}$ ditolak dan $\mathrm{H}_{1}$ diterima, dan dapat disimpulkan bahwa terdapat perbedaan hasil belajar fisika siswa melalui penerapan model pembelajaran kooperatif tipe Snowball Throwing dan tipe
Talking Stick pada siswa kelas XI SMA Khatolik Santo Andreas Palu.

\section{B. Pembahasan}

Penelitian dilakukan dengan cara memberikan dua perlakuan yang berbeda yaitu pembelajaran tipe snowball throwing di kelas eksperimen 1 dan pembelajaran tipe talking stick di kelas eksperimen 2.

Berdasarkan hasil pengolahan data yang dilakukan, dilihat bahwa kemampuan awal siswa masih rendah. Hal ini dapat diketahui dari pemberian tes awal (pretest) pada kelas XI IPA 1 dengan skor rata-rata sebesar 12,10 sedangkan skor rata-rata pada kelas XI IPA 2 sebesar 15,80 . Untuk pemberian tes akhir (posttest) pencapaian skor rata-rata pada kelas eksperimen 1 (XI IPA 1) sebesar 25,30 sedangkan pada kelas eksperimen 2 (XI IPA 2) sebesar 21,90. Dari hasil penelitian tersebut dapat diketahui bahwa skor rata-rata kelas eksperimen 1 lebih tinggi daripada kelas eksperimen 2. Kemudian berdasarkan uji normalitas posttest bahwa data yang diperoleh terdistribusi normal dan mempunyai varians yang homogen.

Berdasarkan hasil penelitian tersebut dapat diketahui bahwa dengan memberikan perlakuan yang berbeda pada kelas eksperimen 1 dan kelas eksperimen 2, akan memperoleh hasil belajar yang berbeda. Perbedaan hasil belajar tersebut dapat dilihat pada skor rata-rata tes akhir (posttest) pada kelas eksperimen 1 dan kelas eksperimen 2 yang menunjukkan adanya pengaruh model pembelajaran yang digunakan pada kedua kelas tersebut.

Hasil belajar yang lebih besar terjadi pada kelas eksperimen ke-1, karena tipe snowball throwing lebih menuntut siswa yang aktif dalam proses belajar serta memberikan kesempatan bagi siswa membuat pertanyaan dan menjawab pertanyaan mereka sendiri. Bila dibandingkan dengan kelas eksperimen ke-2 yaitu tipe talking stick, siswa terlihat gugup dan kurang konsentrasi dalam menjawab soal yang mengakibatkan siswa yang dalam keadaan normal seharusnya bisa menjawab pertanyaan dengan benar, dapat mengalami lupa karena terlalu gugup. Keaktifan siswa lebih terbatas dikarenakan siswa hanya aktif menjawab pertanyaan dan tidak dikembangkan untuk membuat pertanyaan seperti dalam tipe snowball throwing. 
Hasil penelitian ini sama dengan penelitian sebelumnya Sau [5] yang menyatakan bahwa hasil belajar siswa pada kelas yang menggunakan model pembelajaran Snowball Throwing lebih baik dari pada kelas yang menggunakan model pembelajaran Talking Stick. Penelitian yang dilakukan oleh Pramukantoro [6] bahwa pembelajaran dengan menggunakan perpaduan metode pembelajaran Snowball Throwing dengan Talking Stick berpengaruh signifikan lebih tinggi terhadap hasil belajar siswa dibandingkan sebelum diberi pembelajaran dengan metode tersebut. Hal ini sesuai dengan penelitian yang telah dilakukan bahwa terdapat perbedaan hasil belajar fisika siswa dengan menggunakan model pembelajaran kooperatif tipe snowball throwing dan tipe talking stick.

Dari hasil temuan tersebut dapat dilihat kedua tipe tersebut sama-sama dapat meningkatkan hasil belajar siswa. Tetapi yang menjadi perbedaan antara kelas eksperimen 1 yang menggunakan model pembelajaran kooperatif tipe Snowball Throwing yang menitikberatkan pada kemampuan merumuskan pertanyaan yang dikemas dalam sebuah permainan yang menarik yaitu saling melemparkan bola salju (Snowball Throwing) yang berisikan pertanyaan kepada sesama siswa lain yang masing-masing siswa menjawab pertanyaan dari bola yang diperoleh. Kelebihan dari tipe Snowball Throwing yaitu saling memberikan/berbagi pengetahuan antara siswa yang kurang dengan siswa yang menonjol prestasi belajarnya dan siswa dapat lebih aktif, karena siswa yang berusaha menemukan sendiri jawaban dari pertanyaan. Kekurangan dari tipe Snowball Throwing yaitu pengetahuan tidak luas hanya berkutat pada pengetahuan sekitar siswa.

Sedangkan kelas eksperimen 2 yang menggunakan model pembelajaran kooperatif tipe Talking Stick yang dengan bantuan tongkat, siapa yang memegang tongkat wajib menjawab pertanyaan dari guru setelah siswa mempelajari materi yang ditentukan. Kelebihan dari tipe Talking Stick yaitu melatih siswa membaca dan memahami lebih cepat. Kekurangan dari tipe Talking Stick yaitu siswa merasa kaget dan takut atas sikap guru yang mengajukan pertanyaan. Perbedaan tersebut menunjukkan adanya pengaruh model pembelajaran yang digunakan pada kelas eksperimen 1 dan kelas eksperimen 2.

\section{KESIMPULAN DAN SARAN}

\section{A. Kesimpulan}

Berdasarkan hasil dan analisis data penelitian yang diperoleh, maka dapat disimpulkan bahwa terdapat perbedaan hasil belajar fisika melalui penerapan model pembelajaran kooperatif tipe Snowball Throwing dan tipe Talking Stick pada siswa kelas XI SMA Khatolik Santo Andreas Palu. Hal ini berdasarkan uji statistik yaitu uji-t diperoleh $t_{\text {hitung }}=2,46>t_{\text {tabel }}=2,02$ yang menunjukkan bahwa $\mathrm{H}_{1}$ diterima sedangkan $\mathrm{H}_{0}$ ditolak. Dari hasil penelitian dapat diketahui bahwa skor rata-rata kelas eksperimen ke-1 (tipe Snowball Throwing) lebih tinggi yaitu 25,30 daripada kelas eksperimen ke-2 (tipe Talking Stick) yaitu 21,90 .

\section{B. Saran}

Beberapa kendala yang dialami penulis selama melakukan penelitian diantaranya, keseriusan siswa yang kurang, kurang patuhnya siswa dengan perintah guru, dan waktu yang kurang efisien dalam menerapkan model pembelajaran. Oleh sebab itu penulis mengajukan beberapa saran : (1) Guru perlu memotivasi siswa agar lebih aktif dan serius dalam kegiatan belajar. (2) Dalam menggunakan model pembelajaran kooperatif tipe snowball throwing dan tipe talking stick di perlukan perencanaan alokasi waktu yang baik.

\section{DAFTAR PUSTAKA}

[1] M.N. Yahya. dan J.A. Pramukantoro. "Pengembangan Perangkat Model Pembelajaran Kooperatif Tipe Talking Stick Pada Standar Kompetensi Mengoprasikan Peralatan Pengendali Daya Tegangan Rendah Di SMKN 2 Surabaya". Jurnal Penelitian Pendidikan Elektro. 01, (1), 95-103. (013.

[2] Slameto. Belajar Dan Faktor-Faktor Yang Mempengaruhi. Jakarta: Rineka Cipta

[3] K.Y. Gintoe, Y. Kendek, dan A. Hatibe. "Pengaruh Model Pembelajaran Kooperratif Tipe Talking Stick Terhadap Hasil Belajar IPA Fisika Pada Siswa Kelas VII SMP Negeri 9 Palu". Jurnal pendidikan fisika tadulako (JPFT), 3, (4), 1-12. 2010.

[4] S. Arikunto. Prosedur Penelitian: Suatu Pendekatan Praktik. Jakarta: PT. Rineka Cipta. 2006.

[5] Y. Sau. "Perbedaan Hasil Belajar Siswa Melalui Penerapan Model Pembelajaran Kooperatif Tipe Snowball Throwing Dan Tipe Talking Stick Pada Mata Pelajaran IPS Terpadu Kelas VII SMP Negeri 1 Botumoito". Jurnal Jurusan Pendidikan Ekonomi. Vol.6, (1), 42-49. 2014.

[6] A.J. Pramukantoro, dan Hafid, A. "Pengaruh Perpaduan Metode Pembelajaran Snowball Throwing Dengan Talking Stick Terhadap Hasil Belajar Siswa 
Jurnal Pendidikan Fisika Tadulako Online (JPFT)

Vol. 7 No. 1 p-ISSN 2338-3240, e-ISSN 2580-5924

Pada Standar Kompetensi Menerapkan Dasar-Dasar Elektronika". Jurnal Penelitian Pendidikan Teknik

Elektro. 01, (1), 11-20. 2013. 